Tomoko Takeda MD,

Koshi Makita MD,

Seiji Ishikawa MD,

Koh Kaneda MD,

Kuninori Yokoyama BE,

Keisuke Amaha MD

\section{Uptake and elimination of sevoflurane in rabbit tissues - an in vivo magnetic resonance spectroscopy study}

Purpose: Previous pharmacokinetic studies of fluorinated anesthetics using ${ }^{19} \mathrm{~F}$-magnetic resonance spectroscopy $\left({ }^{19} \mathrm{~F}-\mathrm{MRS}\right)$ have focused on the brain. Investigation of other tissues would give more precise information about the pharmacokinetics of inhalational anesthetics. In this study we investigated the pharmacokinetics of uptake and elimination of sevoflurane in brain, liver, muscle, venous blood and arterial blood of rabbits.

Methods: Twenty rabbits were examined by ${ }^{19} \mathrm{~F}-\mathrm{MRS}$ conducted at 4.7 Tesla using a I-cm-diameter surface coil for brain $(n=4)$, liver $(n=5)$ and muscle $(n=5)$, and a I.3-cm-diameter surface coil for arterial $(n=3)$ and venous $(n=3)$ blood. Sevoflurane, 4\% in oxygen, was administered for $120 \mathrm{~min}$, followed by 120 min elimination.

Results: Both the uptake and elimination kinetics were best fitted by a biexponential curve which was divided into fast and slow components. During the uptake experiment the time required to reach half of the maximum spectroscopic intensity in each tissue was $1.6 \mathrm{~min}$ in arterial blood, $4.7 \mathrm{~min}$ in liver, $12.2 \mathrm{~min}$ in venous blood, 14.4 min in brain and 20.9 min in muscle. During the elimination experiment the time required to reach half maximum intensity was $2.4 \mathrm{~min}$ in arterial blood, $6.3 \mathrm{~min}$ in liver, 13.4 min in venous blood, 19.6 min in brain and $28.7 \mathrm{~min}$ in muscle.

Conclusions: Sevoflurane uptake or elimination in the tissues examined followed biexponential kinetics. In this rabbit model, sevoflurane uptake and elimination were fastest in arterial blood, followed, in order, by liver, venous blood, brain and muscle.

Objectif : Les études antérieures sur la pharmacocinétique des anesthésiques fluorés réalisées à l'aide de la ${ }^{19} \mathrm{~F}$-spectroscopie par résonance magnétique ( ${ }^{19} \mathrm{~F}-\mathrm{SRM}$ ) concernaient le cerveau. Des recherches avec d'autres tissus nous donneront des renseignements plus précis sur la pharmacocinétique des anesthésiques d'inhalation. L'objectif de la présente étude est d'investiguer la pharmacocinétique de l'absorption et de l'élimination du sévoflurane au niveau du cerveau, du foie, des muscles, du sang veineux et artériel de lapins.

Méthode : Vingt lapins ont été examinés par ${ }^{19} \mathrm{~F}-\mathrm{SRM}$ menée à 4,7 Tesla en utilisant un serpentin de surface de I cm de diamètre pour le cerveau $(n=4)$, le foie $(n=5)$ et les muscles $(n=5)$, et de $1,3 \mathrm{~cm}$ de diamètre pour le sang artériel $(n=3)$ et veineux $(n=3)$. L'administration de sévoflurane à $4 \%$ mélangé à l'oxygène pendant 120 min a été suivie de 120 min pour mesurer l'élimination.

Résultats : La cinétique de l'absorption et de l'élimination a été ajustée au mieux par une courbe biexponentielle qui a été divisée en composantes lentes et rapides. Pendant la phase d'absorption, le temps requis pour atteindre la demie de l'intensité maximale dans chacun des tissus a été de 1,6 min dans le sang artériel, 4,7 min dans le foie, 12,2 min dans le sang veineux, 14,4 min dans le cerveau et 20,9 min dans les muscles. Pendant la phase d'élimination, le temps nécessaire pour atteindre la moitié de l'intensité maximale a été de 2,4 min dans le sang artériel, 6,3 min dans le foie, 13,4 min dans le sang veineux, 19,6 min dans le cerveau et 28,7 min dans les muscles.

Conclusion : L'absorption ou l'élimination de sévoflurane dans les tissus étudiés obéissait à une cinétique biexponentielle. Chez le lapin, l'absorption et l'élimination du sévoflurane ont été plus rapides dans le sang artériel puis, dans l'ordre, dans le foie, le sang veineux, le cerveau et le muscle.

From the Department of Anesthesiology and Critical Care Medicine, Tokyo Medical and Dental University, 1-5-45 Yushima, Bunkyo-ku, Tokyo 113-8519, Japan.

Address correspondence to: T. Tomoko MD. Phone: 81-3-5803-5323; Fax: 81-3-5803-0149; E-mail: makita.mane@med.tmd.ac.jp Supported in part by Grant-in-Aid for Scientific Research (c)(no.07671646) from the Ministry of Education, Science and Culture of Japan. Accepted for publication March 9, 2000. 
$\mathrm{T}$

$\mathrm{HE}$ introduction of ${ }^{19} \mathrm{~F}$-magnetic resonance spectroscopy ( $\left.{ }^{19} \mathrm{~F}-\mathrm{MRS}\right)$ has made it possible to conduct in vivo pharmacokinetic studies of fluorinated inhalational anesthetics. ${ }^{1}$ Since the brain is a site of anesthetic action, most previous studies using MRS have examined pharmacokinetics in the brain, ${ }^{2-11}$ but the results obtained are controversial. Few studies have examined other tissues. ${ }^{12-14}$ and the pharmacokinetics of anesthetics in tissues other than brain are unclear. Therefore, investigation of other tissues would give more precise information about the pharmacokinetic behaviour of inhalational anesthetics in the whole body.

In this study, we investigated the pharmacokinetics of sevoflurane uptake and elimination in brain, liver, muscle, arterial blood and venous blood of rabbits using in vivo ${ }^{19} \mathrm{~F}$-MRS. As the liver has a special blood supply consisting of the hepatic artery and portal vein, the uptake and elimination pattern in the liver may differ from that in the brain. Venous blood may reflect a composite of the kinetics of those of the individual tissues. We compared the pharmacokinetics of sevoflurane among various tissues, as well as comparing the uptake and elimination in each tissue.

Materials and methods

\section{Animal preparation}

The study was approved by the Institutional Review Board for the care of laboratory animals. Twenty Japanese white rabbits weighing 2.9-3.4 $\mathrm{kg}$ were divided into five groups for investigation of brain $(\mathrm{n}=4)$, liver $(\mathrm{n}=5)$, muscle $(\mathrm{n}=5)$, arterial $(\mathrm{n}=3)$ and venous blood $(n=3)$. The animals were initially anesthetised with ketamine/xylazine $i m$. A catheter was placed in an ear vein for administration of fluid and intravenous anesthetics, and another in a femoral artery for blood gas sampling and blood pressure monitoring. Anesthesia was maintained using intravenous xylazine and ketamine until sevoflurane administration was initiated. A tracheotomy was performed and muscle paralysis was induced by 0.4 $\mathrm{mg} \cdot \mathrm{hr}^{-1}$ pancuronium iv. Ventilation was controlled mechanically to maintain $\mathrm{PaCO}_{2}$ at $40 \pm 5 \mathrm{mmHg}$. Rectal temperature was monitored and a water-circulating heating pad was used to maintain body temperature at $38.0 \pm 1.0^{\circ} \mathrm{C}$. A craniotomy was performed on the rabbits in the brain group to expose a 2.5 3.0 $\mathrm{cm}$ diameter circle of dura. In the muscle group, the right femoral muscle was exposed widely enough to exclude contamination by skin tissue, and in the liver group, the liver was exposed by a laparotomy. In the venous and arterial blood groups, catheters were placed in the carotid artery and the right atrium through the carotid vein. The catheters from the vein and the artery were connected using a circuit tube system $130 \mathrm{~cm}$ in length with a $2.5-\mathrm{ml}$ syringe midway in the circuit. As an accurate magnetic resonance (MR) signal cannot be obtained from a moving object, the pharmacokinetics in venous or arterial blood were measured in the $2.5 \mathrm{-ml}$ syringe. The arterial and venous blood group received $10 \mathrm{mg} \cdot \mathrm{kg}^{-1}$ heparin $i$, before the measurements were made. Either arterial or venous blood was injected into the syringe just before the measurement, and the blood was reinfused into the animal after the measurement.

\section{Magnetic Resonance Spectrometry method}

The ${ }^{19} \mathrm{~F}$-MRS measurements were carried out using a 4.7-T MRS/I system (Unity plus-SIS 200/330, Varian, Palo Alto, Calif) with a magnet bore inner diameter of $33 \mathrm{~cm}$. The resonant frequency of ${ }^{19} \mathrm{~F}$ of our MR system was $188.238 \mathrm{MHz}$. In the brain, liver and muscle groups, a two-turn $1.0-\mathrm{cm}$-diameter surface coil was placed on the surface of each tissue, and the animals were placed in the MR chamber. In the blood groups, one $2.5-\mathrm{ml}$ syringe was connected midway in the circuit described above, and two $5-\mathrm{ml}$ syringes were connected to the arterial and venous sides of the tube. A two-turn $1.3-\mathrm{cm}$-diameter surface coil was wound around the $2.5-\mathrm{ml}$ syringe and it was placed in the MR chamber, the other two syringes being outside the chamber. The magnetic field homogeneity was optimised using shimming coils until the water proton line width was $<35 \mathrm{~Hz}$. Just before collecting the MR spectra, the ketamine infusion was discontinued and the inspired sevoflurane concentration was set at $4.0 \%$ using an anesthetic vaporiser (Sevotec3, Ohmeda). The sevoflurane concentration was measured at the Y-piece of a respiratory circuit using an anesthetic gas analyser (Ultima, Datex) calibrated with a calibration gas. ${ }^{19} \mathrm{~F}-\mathrm{MR}$ spectra were obtained by averaging 128 acquisitions. The acquisition parameters used were a $50-\mathrm{kHz}$ spectral width, $30 \mu \mathrm{sec}$ pulse width, and a $0.2 \mathrm{-sec}$ repetition time. Acquisition of one data took $40 \mathrm{sec}$.

The inspired concentration of sevoflurane, $4 \%$, was delivered in oxygen $100 \%$. Spectroscopic data were obtained during $120 \mathrm{~min}$ of sevoflurane wash-in and during 120 min of sevoflurane wash-out.

In the uptake phase, data collection was performed at $0,1,2,3,4,5,6,8,10,15,20,25,30,40,50,60$, 80,100 , and $120 \mathrm{~min}$ after commencement of sevoflurane. In the elimination phase, data were collected at the same intervals as those for the uptake phase after discontinuation of sevoflurane. For brain, liver and muscle data, the midpoint in the spectral acquisition 
duration was taken as the 'time' value. For arterial and venous blood, the time of sampling was used as the 'time' value. The end-tidal sevoflurane concentration and arterial blood pressure were recorded continuously.

\section{Data analysis}

The sevoflurane MR signal intensity obtained by numerical integration was normalised to the maximum intensity that was observed during the final 40 sec of sevoflurane administration. The naive pooled data method ${ }^{15-17}$ was used for data analysis. In this method, a descriptive structural model is fitted to data from all individuals by treating them as a single individual. The data for each tissue were then fitted to a mono-, bi-, or tri-exponential curve using commercial software (KaleidaGraph, Synergy Software, Reading, PA). The Akaike information criterion (AIC) ${ }^{18,19}$ was used to compare the goodness-of-fit among three curves. The AIC takes into account the number of parameters, and the model that gives the lowest AIC value is considered the best fit. In the same way, the alveolar concentrations of sevoflurane were expressed relative to the alveolar concentration at $120 \mathrm{~min}$ of sevoflurane exposure.

TABLE I Data of wash-in phase. AIC lu is the AIC (Akaike Information Criterion) value obtained from monoexponential curve-fit data of each tissue. AIC $2 u$ is the AIC value obtained from biexponential curve-fit data. AIC $3 \mathrm{u}$ is the AIC value obtained from triexponential curve-fit data. The lowest value of AIC is considered the best fit.

\begin{tabular}{llll}
\hline & $A I C 1 u$ & $A I C 2 u$ & $A I C 3 u$ \\
\hline alveolar & -1865 & -2228 & \\
arterial blood & -230 & -241 & -126 \\
liver & -509 & -539 & -537 \\
venous blood & -296 & -297 & -293 \\
brain & -288 & -324 & -317 \\
muscle & -485 & -499 & -497 \\
\hline
\end{tabular}

TABLE II Constants of the biexponential equation expressed as $\mathrm{Y}=\mathrm{k}_{\mathrm{u} 1} \times\left\{1-\exp \left(-\mathrm{t} / \tau_{\mathrm{u} 1}\right\}+\mathrm{k}_{\mathrm{u} 2} \times\left\{1-\exp \left(-\mathrm{t} / \tau_{\mathrm{u} 2}\right)\right\}\right.$ and derived values in uptake phase. $\tau_{\mathrm{u} 1}$ and $\tau_{\mathrm{u} 2}$ are the time constants of uptake. $\mathrm{k}_{\mathrm{u} 1}$ and $\mathrm{k}_{\mathrm{u} 2}$ are constants that reflect the relative volumes of the fast and slow components. $t_{1 / 2}$ is the time to reach half of the maximum intensity and $\mathrm{t}_{90 \%}$ is the time to reach $90 \%$ of the maximum intensity.

\begin{tabular}{lllllll}
\hline & $k_{u 1}$ & $\begin{array}{l}\tau_{u 1} \\
(\text { min })\end{array}$ & $k_{u 2}$ & $\begin{array}{l}\tau_{u 2} \\
(\text { min })\end{array}$ & $\begin{array}{l}t_{u 1 / 2} \\
(\text { min })\end{array}$ & $\begin{array}{l}t_{90 \%} \\
(\text { min })\end{array}$ \\
\hline alveolar & 0.77 & 0.37 & 0.21 & 7.39 & 0.4 & 7.14 \\
arterial blood & 0.70 & 1.41 & 0.33 & 22.0 & 1.6 & 20.5 \\
liver & 0.48 & 4.00 & 0.46 & 10.3 & 4.7 & 25.4 \\
venous blood & 0.54 & 9.96 & 0.49 & 43.8 & 12.2 & 58.6 \\
brain & 0.25 & 3.12 & 0.80 & 38.0 & 14.4 & 63.6 \\
muscle & 0.07 & 0.245 & 0.97 & 35.7 & 20.9 & 69.1 \\
\hline
\end{tabular}

Results

The AIC values of mono-, bi-, and tri-exponential curve-fitting during the uptake phase are shown in Table I. The alveolar concentration ratio was not curve-fitted to a triexponential curve in the uptake phase, as the third term became negative. The AIC values show that the obtained data were best fitted by a biexponential curve for each tissue, denoted by the formula: $\mathrm{Y}=\mathrm{k}_{\mathrm{u} 1} \times\left\{1-\exp \left(-\mathrm{t} / \tau_{\mathrm{u} 1}\right\}+\mathrm{k}_{\mathrm{u} 2} \times\left\{1-\exp \left(-\mathrm{t} / \tau_{\mathrm{u} 2}\right)\right\}\right.$, where $\mathrm{Y}$ is the relative intensity of the spectrum obtained at time point $t, \tau_{\mathrm{u} 1}$ and $\tau_{\mathrm{u} 2}$ are the time constants of the fast and slow components of uptake respectively, and $\mathrm{k}_{\mathrm{u} 1}$ and $\mathrm{k}_{\mathrm{u} 2}$ are constants that reflect the relative volumes of the fast and slow components in each tissue. The corresponding values of $\mathrm{k}_{\mathrm{ul}}, \mathrm{k}_{\mathrm{u} 2}$ $\tau_{\mathrm{u} \mathrm{b}}$ and $\tau_{\mathrm{u} 2}$ are shown in Table II. The biexponential curve-fit of sevoflurane uptake by five tissues and that of the end-tidal sevoflurane concentration are shown in Figure 1. The end-tidal sevoflurane concentration reached a plateau rapidly during the uptake phase. Less than 10 min after the start of inhalation, the endtidal sevoflurane concentration reached $90 \%$ of the maximum concentration. In the brain, for example,

TABLE III Data of wash-out phase. AIC le is the AIC (Akaike Information Criterion) value obtained from monoexponential curve-fit data of each tissue. AIC $2 \mathrm{e}$ is the AIC value obtained from biexponential curve-fit data. AIC $3 \mathrm{e}$ is the AIC value obtained from triexponential curve-fit data. The lowest value of AIC is considered the best fit.

\begin{tabular}{llll}
\hline & AIC 1e & AIC 2e & AIC 3e \\
\hline alveolar & -2157 & -3017 & -1518 \\
arterial blood & -221 & -249 & -248 \\
liver & -391 & -477 & -475 \\
venous blood & -253 & -297 & -296 \\
brain & -365 & -481 & -479 \\
muscle & -485 & -519 & -518 \\
\hline
\end{tabular}

TABLE IV Constants of the biexponential equation expressed as $\mathrm{Y}=\mathrm{k}_{\mathrm{e} 1} \times \exp \left(-\mathrm{t} / \tau_{\mathrm{e} 1}\right)+\mathrm{k}_{\mathrm{e} 2} \times \exp \left(-\mathrm{t} / \tau_{\mathrm{e} 2}\right)$. and derived values in elimination phase. $\tau_{\mathrm{e} 1}$ and $\tau_{\mathrm{e} 2}$ are the time constants of the fast and slow components of elimination. $\mathrm{k}_{\mathrm{e} 1}$ and $\mathrm{k}_{\mathrm{e} 2}$ are constants that reflect the relative volumes of the fast and slow components in each tissue. $t_{\mathrm{el}_{2}}$ is the time to reach half of the maximum intensity and $\mathrm{t}_{10 \%}$ is the time to reach $10 \%$ of the maximum intensity.

\begin{tabular}{lllllll}
\hline & $k_{e 1}$ & $\begin{array}{l}\tau_{e 1} \\
(\text { min })\end{array}$ & $k_{e 2}$ & $\begin{array}{l}\tau_{e 2} \\
(\text { min })\end{array}$ & $\begin{array}{l}t_{e 1 / 2} \\
(\text { min })\end{array}$ & $\begin{array}{l}t_{10 \%} \\
(\text { min })\end{array}$ \\
\hline alveolar & 0.79 & 0.483 & 0.20 & 25.6 & 0.46 & 17.7 \\
arterial blood & 0.62 & 1.75 & 0.37 & 32.9 & 2.4 & 43.0 \\
liver & 0.73 & 5.38 & 0.29 & 116 & 6.3 & 124 \\
venous blood & 0.50 & 7.20 & 0.50 & 79.6 & 13.4 & 128 \\
brain & 0.49 & 9.58 & 0.50 & 145 & 19.6 & 233 \\
muscle & 0.36 & 17.2 & 0.62 & 79.3 & 28.7 & 145 \\
\hline
\end{tabular}




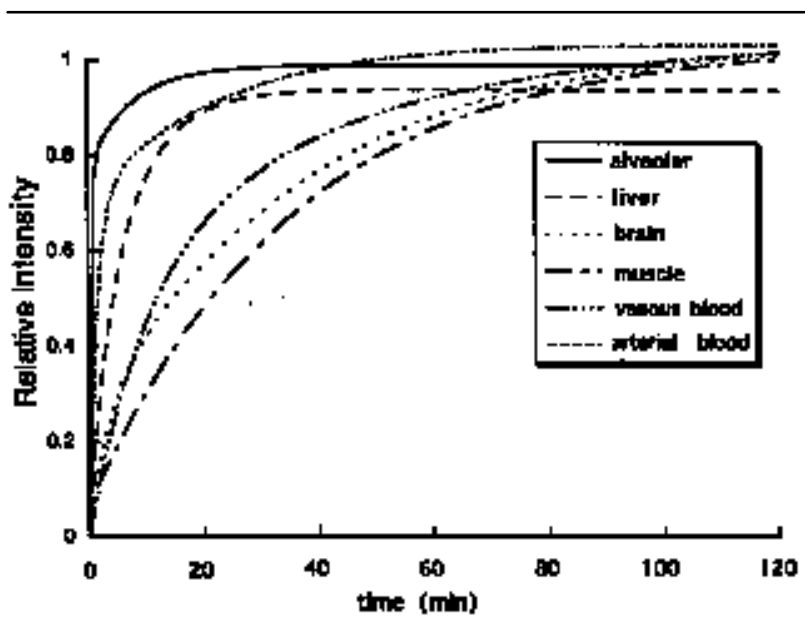

FIGURE 1 Biexponential curves for sevoflurne uptake in rabbit tissues. Each line shows curve which is best fitted to biexponential function denoted as $\mathrm{Y}=\mathrm{k}_{\mathrm{u} 1} \times\left\{1-\exp \left(-\mathrm{t} / \tau_{\mathrm{u} 1}\right\}+\mathrm{k}_{\mathrm{u} 2} \times\left\{1-\exp \left(-\mathrm{t} / \tau_{\mathrm{u} 2}\right)\right\}\right.$. Time value means time after starting sevoflurane inhalation. See text for details.

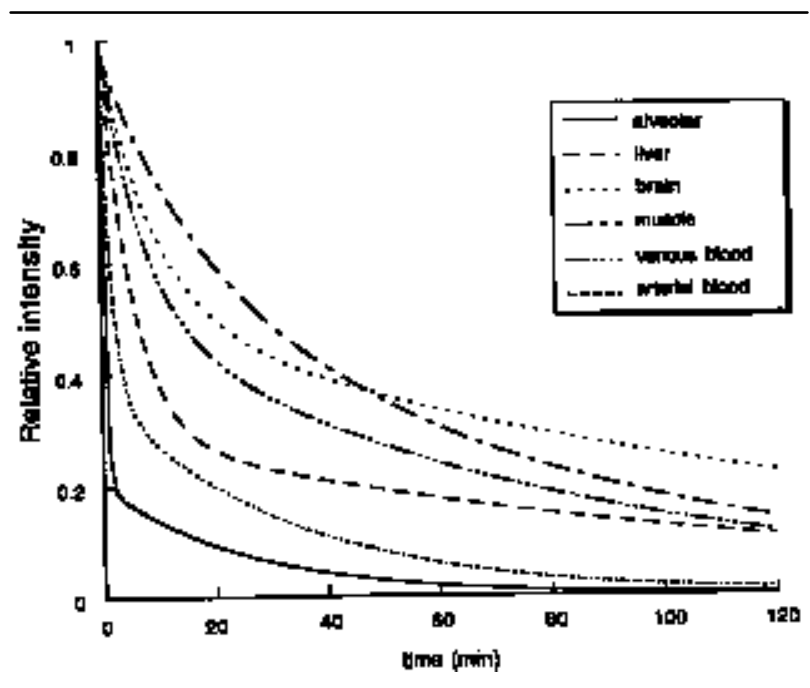

FIGURE 2 Biexponential curves for sevoflurne elimination in rabbit tissues. Each line shows curve which is best fitted to biexponential function denoted as $\mathrm{Y}=\mathrm{k}_{\mathrm{e} 1} \times \exp \left(-\mathrm{t} / \tau_{\mathrm{e} 1}\right)+\mathrm{k}_{\mathrm{e} 2} \times \exp \left(-\mathrm{t} / \tau_{\mathrm{e} 2}\right)$. Time value means time after discontinuing sevoflurane inhalation. See text for details.

$25 \%$ of sevoflurane uptake occurred rapidly at a time constant of $3.12 \mathrm{~min}$, and $80 \%$ of sevoflurane uptake occurred slowly at a time constant of $38.0 \mathrm{~min}$. Uptake of sevoflurane in arterial blood occurred predominantly $(70 \%)$ in the rapid phase $\left(\tau_{\mathrm{ul}}=1.4 \mathrm{~min}\right)$.
The AIC values of mono-, bi-, and tri-exponential curve-fitting in the elimination phase are shown in Table III. The AIC values show that the obtained data were best fitted to a biexponential curve best for each tissue, denoted by the formula $\mathrm{Y}=\mathrm{k}_{\mathrm{el}} \times \exp (-$ $\left.\mathrm{t} / \tau_{\mathrm{e} 1}\right)+\mathrm{k}_{\mathrm{e} 2} \times \exp \left(-\mathrm{t} / \tau_{\mathrm{e} 2}\right)$, where $\tau_{\mathrm{e} 1}$ and $\tau_{\mathrm{e} 2}$ represent the time constants of the fast and slow components of elimination, and $\mathrm{k}_{\mathrm{el}}$ and $\mathrm{k}_{\mathrm{e} 2}$ are constants representing the relative volumes of the fast and slow components of elimination in each tissue. The corresponding values of $\mathrm{k}_{\mathrm{e} 1}, \mathrm{k}_{\mathrm{e} 2}, \tau_{\mathrm{e} 1}$, and $\tau_{\mathrm{e} 2}$ are shown in Table IV. The biexponential curve-fit of sevoflurane elimination from rabbit tissues is shown in Figure 2. The end- tidal concentration of sevoflurane decreased rapidly from $100 \%$ to $10 \%$ of the maximum concentration in $18 \mathrm{~min}$. Among the five tissues tested, sevoflurane elimination was fastest in arterial blood, followed in order by liver, venous blood, brain, and muscle.

\section{Discussion}

The uptake and elimination curves both gave best fits for biexponential curves. Namely, the uptake and elimination of the inhaled anesthetics by each tissue were each divided into a fast component and a slow component. The time constants of the fast and the slow components and the relative volumes $\left(\mathrm{k}_{\mathrm{u}}, \mathrm{k}_{\mathrm{u} 2}\right.$, $\mathrm{k}_{\mathrm{e} 1}$ and $\mathrm{k}_{\mathrm{e} 2}$ ) of each component differed between the tissues, and also between the uptake and elimination phases in individual tissues.

Uptake of sevoflurane in brain was distinctly slower than in arterial blood and liver, and it took longer to reach equilibrium. However, it was still much faster than the rate of halothane uptake reported by Venkatasubramanian et al. ${ }^{0}$ Their NMR method was similar to ours in that a surface coil was positioned over the brain. In our study the time required to reach $90 \%$ of maximum intensity was $63.6 \mathrm{~min}$, whereas for halothane it was 194 266 min (calculated from their data). The concentration and duration of inhalation differed between their study and ours, but it appears that long duration anesthesia with sevoflurane does not cause accumulation of sevoflurane in the brain, and does not cause delayed recovery, compared with halothane. Elimination of sevoflurane from the brain was slower than its uptake. Our kinetic data for sevoflurane uptake $\left(\mathrm{t}_{\mathrm{ul} / 2}\right.$ and $\left.\mathrm{t}_{\mathrm{u} 90 \%}\right)$ and elimination in the rabbit brain are similar to the results of $\mathrm{Xu}$ et al., ${ }^{11}$ who reported $\mathrm{t}_{\mathrm{ul} / 2}$ and $\mathrm{t}_{\mathrm{u} 90 \%}$ values of approximately 18 and 53 min respectively (from their graph) and $\mathrm{t}_{\mathrm{el} / 2}$ and $\mathrm{t}_{\mathrm{e} 10 \%}$ values of $32.4 \mathrm{~min}$ and $230 \mathrm{~min}$ respectively (calculated from their results). In our study the time required to reach half of the maximum intensity $\left(t_{\mathrm{el} / 2}\right)$ was $19.6 \mathrm{~min}$, and this value was smaller than that for 
isoflurane ( $36 \pm 5 \mathrm{~min})$ measured by a similar method. ${ }^{7}$ It took $233 \mathrm{~min}$ to eliminate $90 \%$ of the sevoflurane from brain according to our results, although this seems unlikely to be the case in the human brain based on our clinical experience. Concerning these results, we must consider the phamacokinetic differences between rabbits and adult humans. The uptake or elimination time constant may be defined as $=($ tissue volume $\times$ tissue/blood partition coefficient)/tissue blood flow. ${ }^{20}$ The tissue volume detected by the surface coil does not change, so only two of these parameters change: the tissue blood flow (inhomogeneity in the same tissue) and/or the tissue/blood partition coefficient (for example grey and white matter in the brain). Mutch et al. ${ }^{21}$ reported that CBF in rabbits is $68-86 \mathrm{ml} \cdot 100 \mathrm{~g} \mathrm{~g}^{-1} \cdot \mathrm{min}^{-1}$, which is similar to that in humans $\left(45-60 \mathrm{ml} \cdot 100 \mathrm{~g}^{-1} \cdot \mathrm{min}^{-1}\right)$. On the other hand, the ratio of white matter and grey matter components differs between humans and rabbits, and this may be responsible for the difference between the two species in the brain/blood coefficient of sevoflurane. Therefore, we cannot apply this result to our clinical experience because of the pharmacokinetic differences between rabbits and humans.

In a previous study by Venkatasubramanian et al., ${ }^{10}$ halothane uptake kinetics for both rabbit brain and arterial blood were reported to be fitted best to a biexponential curve. They suggested that the likely sources of the two components was the grey matter and white matter of the brain, and the plasma and erythrocytes of the arterial blood. Their suggestion may have been based partly on their observation that the ratio of the uptake volumes of the fast and slow components in arterial blood was 1:1 in their experiment. However, in our experiment, the same ratio in arterial blood was $7: 3$ $\left(\mathrm{k}_{\mathrm{u} 1}: \mathrm{k}_{\mathrm{u} 2}\right)$, moreover, the ratio in venous blood was $2: 8$ changing to approximately $1: 1$ during elimination. In brain, the relative volume of the fast and slow components during the uptake phase $\left(k_{u_{1}}\right.$ and $\left.k_{u_{2}}\right)$ also changed during elimination. These results mean that the two components do not arise only from the plasma and erythrocytes or the white and grey matter. From our study, we could not clearly identify the sources of the two components. However we hypothesise that blood flow in a certain tissue is not homogeneous and that it can be divided into a part with relatively abundant flow and a part with relatively scarce flow. The former represent fast uptake and elimination and the latter relatively slow uptake and elimination. The inhomogeneity of blood flow distribution in each tissue ${ }^{22}$ and recirculation of arterial blood may be sources of multiexponential kinetics, but the overall result may still follow biexponential kinetics.
The methods used to obtain NMR signals have differed among previous studies. Wyrwicz et al. ${ }^{1}$ and others $^{3-5}$ used a surface coil over the calvaria and elimination was slow, as the surrounding brain tissue was contaminated. Mills et al. ${ }^{7}$ compared isoflurane elimination over the exposed dura using a $3-\mathrm{cm}$-diameter surface coil and a $1-\mathrm{cm}$ surface coil and obtained rapid elimination from the small $1-\mathrm{cm}$ coil. They thought that the ${ }^{19} \mathrm{~F}-\mathrm{NMR}$ signal arose from other tissues using the large coil. Therefore, we anticipated that sufficient exposure of the dura might yield a more accurate signal from the brain.

One-dimensional chemical shift imaging (CSI) provides a localisation method for observing signals from different locations in a subject. ${ }^{9}, 10$ Venkatasubramanian ${ }^{9}$ compared the uptake of halothane between the surface coil-localised one pulse experiment and a CSI experiment, and found that the rates of uptake in the two methods were similar. The CSI localisation technique required 17 min per data set, so it was thought that a surface coil would reflect the signal more accurately in the early experimental period.

Alveolar uptake and elimination were assessed by Stephen et al. ${ }^{8}$ and compared with data for the brain. They assumed that the cerebral concentration of anesthetics was proportional to the cerebral partial pressure, and that end-tidal, arterial and cerebral partial pressures were equal after $30 \mathrm{~min}$ of equilibration. We also assumed that each tissue would reach equilibration after $120 \mathrm{~min}$ exposure to sevoflurane. This was one of the restrictions in our experiment because, as shown in Figure 1, sevoflurane uptake in muscle did not reach equilibration after 120 min exposure.

Stern et al. ${ }^{12}$ compared NMR methods with nonNMR methods in which they measured tissue sevoflurane concentration by gas chromatography concurrently. They found that the anesthetic concentration in adipose tissue measured by gas chromatography was consistently higher for sevoflurane than that measured by NMR, although this did not affect the absolute value of the time constants of elimination.

In conclusion, the uptake and elimination kinetics of sevoflurane in rabbit brain, liver, muscle, arterial blood and venous blood gave best fits to biexponential curves with fast and slow components. The relative volumes of the fast and slow components changed between uptake and elimination. Sevoflurane uptake and elimination kinetics in arterial blood were rapid and similar to the end-tidal sevoflurane kinetics. Sevoflurane uptake and elimination were fastest in arterial blood, followed in order by liver, venous blood, brain and muscle. Further studies will be necessary to obtain more detailed data on the uptake and elimination pharmacokinetics of flu- 
orinated anesthetics, making comparison between different NMR methods, and also between NMR and non-NMR methods.

Acknowledgments

This study was supported by a Grant-in-Aid for Scientific Research (c)(No.07671646) from the Ministry of Education, Science and Culture of Japan.

References

1 Wyrwicz AM, Pszenny MH, Schofield JC. Noninvasive observations of fluorinated anesthetics in rabbit brain by fluorine-19 nuclear magnetic resonance. Science 1983; 222: 428-30.

2 Strum DP, Johnson BH, Eger EI II. Elimination of anesthetics from rabbit brain. Science 1986; 234 : 1586-8.

3 Wyrwicz AM, Conboy CB, Nichols BG, Ryback KR, Eisele $P$. In vivo ${ }^{19} \mathrm{~F}-\mathrm{NMR}$ study of halothane distribution in brain. Biochim Biophys Acta 1987; 929 : 271-7.

4 Wyrwicz AM, Conboy CB, Ryback KR, Nichols BG, Eisele $P$. In vivo ${ }^{19} \mathrm{~F}-\mathrm{NMR}$ study of isoflurane elimination from brain. Biochim Biophys Acta 1987; 927 : 86-91.

5 Litt L, Gonzáles Méndez R, James TL, et al. An in vivo study of halothane uptake and elimination in the rat brain with fluorine nuclear magnetic resonance spectroscopy. Anesthesiology 1987; 67: 161-8.

6 Evers AS, Berkowitz BA, d'Avignon DA. Correlation between the anaesthetic effect of halothane and saturable binding in brain. Nature 1987; 328: 157-60.

7 Mills P, Sessler DI, Moseley M, et al. An in vivo ${ }^{19} \mathrm{~F}$ nuclear magnetic resonance study of isoflurane elimination from the rabbit brain. Anesthesiology 1987; 67: 169-73.

8 Lockbart SH, Cohen Y, Yasuda N, et al. Cerebral uptake and elimination of desflurane, isoflurane, and halothane from rabbit brain: an in vivo NMR study. Anesthesiology 1991; 74: 575-80.

9 Venkatasubramanian PN, Shen YJ, Wyrwicz AM. In vivo ${ }^{19} \mathrm{~F}$ one-dimensional chemical shift imaging study of isoflurane uptake in rabbit brain. NMR Biomed 1993; 6: 377-82.

10 Venkatasubramanian PN, Shen $\Upsilon$-J, Wyrwicz AM. In vivo ${ }^{19} \mathrm{~F}-\mathrm{NMR}$ spectroscopic study of halothane uptake in rabbit brain. Biochim Biophys Acta 1995; 1245 : 262-8.

$11 X u \Upsilon$, Tang P, Zhang W, Firestone L, Winter PM Fluorine-19 nuclear magnetic resonance imaging and spectroscopy of sevoflurane uptake, distribution, and elimination in rat brain. Anesthesiology 1995; 83: 766-74.
12 Stern RC, Towler SC, White PF, Evers AS. Elimination kinetics of sevoflurane and halothane from blood, brain, and adipose tissue in the rat. Anesth Analg 1990; 71: 658-64.

13 Preece NE, Challands J, Williams SCR. ${ }^{19} \mathrm{~F}$ NMR studies of enflurane elimination and metabolism. NMR Biomed 1992; 5: 101-6.

14 Hashimoto T, Ikehira H, Fukuda H, Ueshima $\Upsilon$, Tateno $\Upsilon$. Study of biodistribution of enflurane in rats with in vivo ${ }^{19} \mathrm{~F}$ MRI. Magn Reson Imaging 1991; 9: 577-81.

15 Wright PMC. Population based pharmacokinetic analysis: why do we need it; what is it; and what has it told us about anaesthetics? Br J Anaesth 1998; 80: 488-501.

16 Sheiner $L B$. The population approach to pharmacokinetic data analysis: rationale and standard data analysis methods. Drug Metab Rev 1984; 15: 153-71.

17 Somma J, Donner A, Zomorodi K et al. Population pharmadynamics of midazolam administration by target controlled infusion in SICU patients after CABG surgery. Anesthesiology 1998; 89: 1430-43.

18 Perrella FW. EZ-FIT: a practical curve-fitting microcomputer program for the analysis of enzyme kinetic data on IBM-PC compatible computers. Anal Biochem 1988; 174: 437-47.

19 Yamaoka K, Nakagawa T, Uno T. Application of Akaike's Information Criterion (AIC) in the evaluation of linear pharmacokinetic equations. J Pharmacokinet Biopharm 1978; 6: 165-75.

20 Kety SS. The theory and applications of the exchange of inert gas at the lungs and tissues. Kety Pharmacol Rev 1951; 3: 1-41.

21 Mutch WAC, Patel PM, Ruta TS. A comparison of the cerebral pressure-flow relationship for halothane and isoflurane at haemodynamically equivalent end-tidal concentrations in the rabbit. Can J Anaesth 1990; 37: 223-30.

22 Gustafsson U, Sollevi A, Sirsjö A, Sjöberg F. Effects on skeletal muscle oxygenation and capillary blood flow by adenosine-, sodium nitroprusside- and acetylcholineinduced hypotension. Acta Anesthesiol Scand 1996; 40: 832-7. 